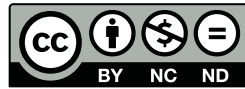

Estudos Teológicos foi licenciado com uma Licença Creative Commons Atribuição - NãoComercial - SemDerivados 3.0 Não Adaptada

http://dx.doi.org/10.22351/et.v.57i2.2727

\title{
A eSPiritualidade dos CUIDAdores informais de PACIENTES EM CUIDADOS PALIATIVOS: UMA REFLEXÃO BIOÉTICA NA PERSPECTIVA DA ALTERIDADE ${ }^{1}$
}

The spirituality of informal caregivers in palliative care: a bioethical reflexion in the perspective of alterity

\section{Maria Leonor Gomes de Sá Vianna² Waldir Souza ${ }^{3}$}

\begin{abstract}
Resumo: A presente pesquisa tem como objetivo avaliar a espiritualidade de cuidadores informais de pacientes em cuidados paliativos por doença oncológica e realizar uma reflexão bioética sobre o princípio da alteridade. A metodologia utilizada foi pesquisa de campo e é classificada como exploratória e quantitativa. Foi realizada entrevista individual a 46 cuidadores informais de cuidados paliativos internados no período de abril a dezembro de 2014 em um hospital universitário da cidade de Curitiba/PR, com resposta a um questionário sociodemográfico, uma escala de espiritualidade Underwood's Daily Spiritual Experience Scale (DSES) e os Quadros de Espiritualidade Fica e Spirit. Em sua maioria, os cuidadores relatam experiências espirituais diárias e descrevem que as atitudes de atenção e dedicação da equipe estão diretamente relacionadas ao grau de satisfação com o cuidado. Compreendendo a espiritualidade como uma dimensão da vida, e que essa faz parte do processo de cuidar, o profissional da saúde poderá, com uma abordagem adequada e por meio do princípio da alteridade, diagnosticar, intervir e avaliar o cuidado espiritual, no sentido de promover o melhor conforto possível, respeitando as necessidades individuais do paciente e seus cuidadores enquanto ser humano.
\end{abstract}

Palavras-chave: Espiritualidade. Cuidados paliativos. Cuidador informal.

1 O artigo foi recebido em 06 de abril de 2016 e aprovado em 03 de junho de 2017 com base nas avaliações dos pareceristas ad hoc.

2 Mestra em Bioética. Professora do curso de Fisioterapia da Pontifícia Universidade Católica do Paraná, Curitiba, Paraná, Brasil. Contato: maria.vianna@pucpr.br

3 Doutor em Teologia. Professor do Programa de Pós-Graduação em Bioética e de Teologia da Pontifícia Universidade Católica do Paraná. Líder do Grupo de Pesquisa Bioética, Humanização e Cuidado na Saúde. Pontifícia Universidade Católica do Paraná/CNPq. Curitiba, Paraná, Brasil. Contato: waldir.souza@pucpr. br; wacasouza@yahoo.com.br 
Abstract: This research aims to evaluate the spirituality of informal caregivers of patients in palliative care for oncological diseases, and perform a bioethical reflection on the principle of otherness. The methodology was field research and is classified as exploratory and quantitative. Forty six informal caregivers of hospitalized palliative care in the period of April to December 2014 at a university hospital in the city of Curitiba (Brazil) filled in a sociodemographic questionnaire, an Underwood's Daily Spiritual Experience Scale (DSES), and the Tables Fica (Puchalski) and Spirit (Maugans). Most caregivers reported daily spiritual experiences, and described the staff's attitudes of attention and dedication directly related to the degree of satisfaction with the care. Spiritual care is characterized by understanding, relating, communicating, interacting and being with others. If spirituality is understood as a life's dimension, and as part of the care process, the health professional can through the principle of otherness with an appropriate approach, diagnose, intervene and evaluate the spiritual care in order to provide the patient with the best possible comfort, respecting his individual needs and their families' as human beings.

Keywords: Spirituality. Palliative care. Informal caregiver.

\section{Introdução}

O conceito de cuidados paliativos teve sua origem na década 1970 com o movimento hospice, idealizado por Cecily Saunders, que descreveu a filosofia do cuidado de pacientes portadores de doenças que não respondem mais ao tratamento curativo com os objetivos de aliviar a dor e o sofrimento físico, psicológico, social e espiritual.

O princípio do cuidado paliativo:

reconhece o valor da vida e olha a morte como um processo normal, não apressa nem adia a morte, trata com eficácia a dor e o sofrimento, integra os aspectos psicológicos e espirituais do cuidado de saúde e oferece um sistema de apoio para que o doente viva tão ativo quanto possível até a sua morte e para que a família suporte o sofrimento com o período final da doença e o luto pela perda do seu familiar ${ }^{4}$.

O cuidado paliativo é uma modalidade de assistência que abrange as dimensões do ser humano além das físicas e emocionais, considera a espiritualidade como fonte de bem-estar aos pacientes e seus familiares. A espiritualidade e a religiosidade têm sido reconhecidas na literatura como recursos que ajudam as pessoas a enfrentar as adversidades do dia a dia e os eventos estressantes e traumáticos, como os relacionados aos processos de adoecimento e hospitalização. ${ }^{5}$

A espiritualidade reflete a essência do ser humano, a força de unificação e ânimo, o princípio da vida de cada indivíduo. Ela nos permite viver, moldar nossa

4 WORLD HEALTH ORGANIZATION. Expert Committee. Cancer, pain relief and palliative care. Geneve, 2002. p. 11.

5 VEIT, Carina Maria; CASTRO Elisa Kern. Coping religioso/espiritual e câncer de mama: uma revisão sistemática da literatura. Psicologia Saúde e doenças, v. 14, n. 1, p. 1-22, 2013. p. 2. Disponível em: $<$ http://www.scielo.mec.pt/pdf/psd/v14n1/v14n1a01.pdf >. Acesso em: 18 set. 2014. 
jornada de vida, e é vital no processo de descoberta dos objetivos, significado de nossas vidas e força interior. ${ }^{6}$ Por intermédio da espiritualidade descobrimos as respostas para questões fundamentais sobre a vida, seu propósito, e a relação com o sagrado ou o transcendente que pode ou não ser experimentada no contexto de uma religião específica. $^{7}$

A percepção da dimensão espiritual é aquele momento da consciência do indivíduo em que ele percebe que é parte de um todo e que pertence a esse todo. ${ }^{8}$ Já a religiosidade é entendida como a extensão na qual o ser humano se envolve com um sistema de crenças, práticas, rituais e símbolos compartilhados por uma comunidade e destinados a facilitar a proximidade com o sagrado ou transcendente. ${ }^{9}$

A espiritualidade e as práticas religiosas são relatadas pelos cuidadores como estratégias eficazes para o enfrentamento da sobrecarga decorrente do processo de cuidar dos pacientes em cuidados paliativos. ${ }^{10}$ A família constitui um dos núcleos centrais na formação de crenças, valores, conhecimentos do indivíduo. E, em geral, quando um membro adoece, toda a família sofre e sente as consequências do momento vivenciado. ${ }^{11}$

Os profissionais da saúde, em seu atendimento, devem contemplar o paciente e seus familiares não mais como um ser passivo e incapaz de ter suas escolhas; a relação profissional paciente e familiar deve ser numa relação simétrica, na qual ambos se contemplam como seres humanos únicos. ${ }^{12}$

Um dos princípios usados como fio condutor para a reflexão bioética é o da alteridade, que recebeu diferentes sentidos: o ser outro, atitude para com o outro, reconhecimento dos outros, enfim, colocar-se no lugar do outro em uma relação baseada no diálogo e na valorização das diferenças existentes. ${ }^{13}$ Pela ótica da alteridade, partimos do pressuposto básico de que toda pessoa social interage e interdepende da outra.

6 DOSSEY Barbara; KEEGAN Lynn. Holistic Nursing. A Handbook for Practice. Seventh Edition Sudbury: Jones and Bartlett Learnig, 2016. p. 143.

7 KOENIG, Harold G.; KING, Dana; CARSON, Verna Benner. Handbook of religion and health, 2nd edition. J. Am Acad Relig., v. 81, n. 2, p. 548-552, 2013. p. 550.

8 BOFF, Leonardo. Espiritualidade: um caminho de transformação. Rio de Janeiro: Sextante, 2006. p. 49.

9 KOENIG, Harold G.; LARSON, David B.; LARSON, Susan S. Religion and coping with serious medical illness. Annals of Pharmacotherapy, v. 35, n. 3, p. 352-359, 2001. p. 356. Disponível em: <http://www. ncbi.nlm.nih.gov/pubmed/11261534>. Acesso em: 12 fev. 2015.

10 ARAUJO, Janete; LEITÃO, Elizabeth Maria Pini. O Cuidador do paciente em cuidados paliativos: sobrecarga e desafios. Revista do Hospital Universitário Pedro Ernesto, Rio de Janeiro, ano 11, p. 77-81, abr./ jun. 2012. p. 79. File://C:/Users/Microsoft/Downloads/8946-31624-1-PB.pdf. Acesso em: 19 dez. 2014.

11 SILVA, Cláudia Adriana Moraes; ARCKER, Justina Inês Brunetto Verruck. V. O cuidado paliativo domiciliar sob a ótica de familiares responsáveis pela pessoa portadora de neoplasia. Rev. Bras. Enferm, Brasília, v. 60, n. 2, p. 150-154, mar./abr. 2007. p. 153. Disponível em: <http://www.scielo.br/pdf/reben/ v60n2/a04v60n2.pdf>. Acesso em: 26 jan. 2015.

${ }^{12}$ CORRÊA, F. A. A alteridade com o critério fundamenta l e englobante e da Bioética. 1993. Tese (Doutorado) - UNICAMP, Campinas, 1993. p. 198.

${ }^{13}$ COSTA, Juliano Xavier Silva; CAETANO, Renato Fernandes. A concepção de alteridade em Lévinas: caminhos para uma formação mais humana no mundo contemporâneo. Revista Eletrônica Igarapé, n. 3, p. 195-210, maio 2014. Disponível em: <http://www.periodicos. unir.br/index.php/igarape/article/ viewFile/861/865>. Acesso em: 15 maio 2015. 
Em razão disso, o "eu" na sua forma individual só pode existir através de um contato com o "outro". ${ }^{14}$

A alteridade tem fundamental aplicação em três critérios da bioética principicialista, que são a beneficência, autonomia e justiça. Em uma definição mais aprofundada, a bioética é o estudo sistemático das dimensões morais, incluindo visão, decisão, conduta e normas morais, das ciências da vida e do cuidado da saúde, utilizando uma variedade de metodologias éticas num contexto interdisciplinar. ${ }^{15}$

O objetivo da presente pesquisa foi avaliar a espiritualidade de cuidadores informais de pacientes em cuidados paliativos por doença oncológica e realizar uma reflexão bioética sobre o princípio da alteridade.

\section{Métodos}

A presente pesquisa é exploratória, descritiva e quantitativa. ${ }^{16}$ A pesquisa de campo foi realizada mediante a aplicação de questionário para caracterização sociodemográfica da amostra dos cuidadores, contendo perguntas relativas à idade, grau de parentesco, estado civil e escolaridade. Utilizaram-se também a escala de espiritualidade Underwood's Daily Spiritual Experience Scale (DSES) ${ }^{17}$ e os quadros de espiritualidade Fica $^{18}$ e Spirit ${ }^{19}$.

A Underwood's Daily Spiritual Experience Scale avalia a frequência com que as pessoas vivenciam, no seu cotidiano, experiências como a sensação da presença de Deus, fortaleza e conforto na religião ou na espiritualidade, conexão com a vida de modo geral, amor aos outros, admiração pela natureza, paz interior, gratidão por bênçãos e desejo de proximidade com Deus, a qual foi adaptada e validada no Brasil. ${ }^{20}$

Os quadros Fica e Spirit avaliam a história religiosa/espiritual do indivíduo e identificam sua importância na vida do paciente e de sua família.

${ }^{14}$ HOSSNE, William Saad; SEGRE, Marco Segre. Dos referenciais da bioética - a Alteridade. Revista Centro Universitário São Camilo, São Paulo, v. 5, n. 1, p. 35-40, 2011. p. 38. Disponível em: <http:// www.saocamilo-sp.br/pdf/bioethikos/82/Art04.pdf>. Acesso em: 22 fev. 2015.

${ }^{15}$ BARCHIFONTAINE, Christian Paul; PESSINI, Leo. Fundamentos da bioética. São Paulo: Paulus, 1996. p. 155 .

${ }^{16}$ LAKATOS, Eva Maria. Metodologia cientifica. 6. ed. São Paulo: Atlas, 2011. p. 52.

${ }^{17}$ UNDERWOOD, Lynn G. The daily spiritual experience scale: overview and results. Religions, v. 2, n. 1, p. 29-50, 2011. p. 39. Disponível em: <http://www.mdpi.com/2077-1444/2/1/29/htm>. Acesso em: 21 jan. 2014.

${ }_{18}$ PUCHALSKI, Christina; ROMER, Anna. L. Taking a spiritual history allows clinicians to understand patients more fully. Journal of Palliative Medicine, v. 3, n. 1, p. 129-137, 2000. p. 132. Disponível em: $<$ http://smhs.gwu.edu/gwish/sites/gwish/files/takingaspiritualhistorypuchalskiromer.pdf $>$. Acesso em: 21 dez. 2014

${ }^{19}$ MAUGANS, T. A. The spiritual history. Archives of Family Medicine, v. 5, n. 1, p. 11-16, 1996. Disponível em: <http://www.ncbi.nlm.nih.gov/pubmed/8542049>. Acesso em: 11 dez. 2014.

${ }^{20}$ MIAKO, Kimura et al. Adaptação cultural e validação da Underwood's Daily Spiritual Experience Scale - versão brasileira. Revista da Escola de Enfermagem da USP, v. 46, n. esp., p. 99-106, 2012. p. 103. Disponível em: <http://www.scielo.br/pdf/reeusp/v46nspe/15.pdf >. Acesso em: 12 jan. 2015. 
Participaram do estudo 46 cuidadores de pacientes internados em cuidados paliativos que preencheram os seguintes critérios de inclusão: ser o cuidador principal do paciente, membro da família ou amigo próximo, ter mais de 18 anos e concordar voluntariamente em participar da pesquisa, assinando o Termo de Consentimento Livre e Esclarecido.

O presente estudo obteve aprovação do Comitê de Ética em Pesquisa em Seres Humanos da Pontifícia Universidade Católica do Paraná, sob o parecer nº 554.960, em 12 de março de 2014. Todos os cuidadores entrevistados foram informados sobre os objetivos do estudo, a confidencialidade das informações e dos resultados e assinaram o Termo de Consentimento Livre e Esclarecido, de acordo com preceitos éticos previstos na Resolução 466/12, do Conselho Nacional de Saúde (CNS).

\section{Resultados e discussão}

Os dados demonstram que os cuidadores informais são casados, apresentam uma média de idade de 44,39 anos, dentro da faixa etária entre 21 a 78 anos, sendo na maioria com grau de parentesco filial com nível de escolaridade do ensino médio completo.

Na escala DSES, que é composta por 16 questões a respeito de experiências espirituais e religiosas, avaliadas entre zero e seis (menores pontuações refletem maior frequência de experiências espirituais na população estudada), o valor médio das primeiras 15 questões indicou um valor de 2,27, o que indica que a maioria dos cuidadores tem experiências espirituais ou religiosas todos os dias. Na décima sexta questão, que pergunta sobre o quanto eles se sentem perto de Deus ou de uma força superior, a maioria relata se sentir muito perto. A soma da média geral de todas as questões foi de 37,34 (Tabela 1).

A respeito de experiências espirituais e religiosas observadas na Underwood's Daily Spiritual Experience Scale (DSES) ${ }^{21}$, as questões indicam que a maioria dos cuidadores tem experiências espirituais ou religiosas todos os dias, o que demonstra uma relação entre a força e o conforto encontrados na religião e na espiritualidade. Outros estudos também demonstraram que tanto os cuidadores como os pacientes com doenças crônicas têm diariamente experiências espirituais. ${ }^{22}$

Frente às dificuldades, alguns familiares buscam na espiritualidade forças para melhor compreender a internação do ente querido e seu estado de saúde. O sofrimento direciona a espiritualidade como forma de superar e estabelecer uma expectativa de melhora do quadro, emergindo, assim, a esperança. ${ }^{23}$

21 UNDERWOOD, 2011, p. 29.

${ }^{22}$ McCAULEY, Jeanne et al. Daily spiritual experiences folder adults with and without arthritis and the relationship to health outcomes. Arthritis Care \& Research, v. 59, n. 1, p. 122-128, 2008. Disponível em: $<$ http://onlinelibrary.wiley.com/doi/10.1002/art.23246/epdf>. Acesso em: 25 jan. 2015.

23 PUGGINA, Ana Claudia Giesbrecht; SILVA, Maria Júlia Paes; ARAUJO, Monica Martins Trovo. Mensagens dos familiares de pacientes em estado de coma: a esperança como elemento comum. Acta Paulista de Enfermagem, v. 21, n. 2, p. 249-255, 2008. Disponível em: <http://www.scielo.br/pdf/ape/ v21n2/pt_a03v21n2.pdf>. Acesso em: 18 dez. 2014. 
Tabela 1 - Underwood's Daily Spiritual Experience Scale (DSES)

\begin{tabular}{lcll}
\hline Questões & $\begin{array}{c}\text { Valor } \\
\text { médio }\end{array}$ & Descritor \\
\hline Eu sinto a presença de Deus. & 2,1 & Todos os dias \\
Eu sinto uma conexão com tudo o que é vida. & 2,28 & Todos os dias \\
Durante um culto religioso ou em outros momentos quando & & \\
estou em conexão com Deus, eu sinto uma alegria que me & & \\
tira das preocupações diárias. & 2,41 & Todos os dias \\
Eu encontro forças na minha religião ou espiritualidade. & 2,17 & Todos os dias \\
Eu encontro conforto na minha religião ou espiritualidade. & 2,17 & Todos os dias \\
Eu sinto profunda paz interior ou harmonia. & 2,32 & Todos os dias \\
Eu peço a ajuda de Deus durante as atividades diárias. & 1,95 & Todos os dias \\
Eu me sinto guiado por Deus durante as atividades diárias. & 2,19 & Todos os dias \\
Eu sinto diretamente o amor de Deus por mim. & 2,17 & Todos os dias \\
Eu sinto o amor de Deus por mim através dos outros. & 2,32 & Todos os dias \\
A beleza da criação me toca espiritualmente. & 2,23 & Todos os dias \\
Eu me sinto agradecido pelas bênçãos recebidas. & 2,06 & Todos os dias \\
Eu sinto carinho desinteressado pelos outros. & 2,6 & Todos os dias \\
Eu aceito os outros mesmo quando eles fazem coisas que eu & & A maioria dos \\
acho que são erradas. & 3 & dias \\
Eu desejo estar mais próximo de Deus ou em união com o & & \\
divino. & 2,13 & Todos os dias \\
Em geral, quanto você se sente perto de Deus? & 3,17 & Muito perto \\
Média geral & $\mathbf{3 7 , 3 4}$ & \\
\hline
\end{tabular}

Fonte: Elaborado pela autora, 2015.

De acordo com a literatura, durante doenças crônicas ou terminais, pacientes e familiares frequentemente se apoiam em crenças religiosas ou espirituais como forma de encarar as dificuldades, encontrar conforto, esperança e força. ${ }^{24} \mathrm{~A}$ espiritualidade é a força da vida unificadora que integra componentes biológicos, psicológicos e sociais, que podem incluir ou excluir o componente religioso, de acordo com o sistema de crenças individuais. ${ }^{25}$

No quadro Fica (espiritualidade), os 46 sujeitos da pesquisa (100\%) se consideram pessoas religiosas ou espiritualizadas, têm fé e relatam que ela é muito importante e dá sentido às suas vidas.

Dentre os sujeitos estudados, $47,83 \%$, são membros de alguma igreja ou comunidade espiritual. Na questão sobre como a equipe pode abordar e incluir a espiri-

${ }^{24}$ CATTANI, Roceli Brum; PERLINI, Nara Marilene Oliveira Girardon. O cuidar do idoso doente no domicílio na voz de cuidadores familiares. Revista Eletrônica de Enfermagem, v. 6, n. 2, 2004. Disponível em: <http://www.revistas.ufg.br/index.php/fen/article/view/812/929>. Acesso em: 16 jan. 2015.

${ }_{25}$ BALDACHINO, Donia. Spiritual care: being in doing. Preca: Library Malta, 2010. p. 35. 
tualidade no atendimento, $45,66 \%$ considera importante tratar com carinho o paciente; $34,78 \%$ dar atenção ao paciente e familiares; $19,56 \%$ demonstrar amor ao trabalho e respeito ao doente; $15,21 \%$ dedicação ao paciente; $10,86 \%$ ter paciência, cuidado, escutar e conversar com pacientes e familiares; 8,69\% demonstrar compaixão; 6,52\% auxiliar nas dificuldades e 4,34\% buscar apoio de pessoas religiosas e pastoral (Tabela 2).

Em um envolvimento com o outro, é preciso entender a necessidade do reconhecimento e da aceitação de si mesmo como pessoa distinta e ter a capacidade de perceber os outros como únicos, o que requer conhecimento, introspecção, autodisciplina, franqueza e liberdade para se revelar como ser humano dotado de emoções e sentimentos. ${ }^{26}$

Tabela 2 - Quadro FICA (Puchalski)

\begin{tabular}{|c|c|c|}
\hline Questões & Frequência & $\begin{array}{c}\text { Porcentagem } \\
(\%)\end{array}$ \\
\hline \multicolumn{3}{|c|}{ Você se considera uma pessoa religiosa ou espiritualizada? } \\
\hline Sim & 46 & 100 \\
\hline Não & 0 & 0 \\
\hline \multicolumn{3}{|c|}{ Tem alguma fé? Se não, o que dá sentido à sua vida? } \\
\hline Sim & 46 & 100 \\
\hline Não & 0 & 0 \\
\hline \multicolumn{3}{|c|}{ A fé é importante em sua vida? Quanto? } \\
\hline Sim & 46 & 100 \\
\hline Muito importante ou importante & 46 & 100 \\
\hline \multicolumn{3}{|c|}{ Você é membro de alguma igreja ou comunidade espiritual? } \\
\hline Sim & 22 & 47,83 \\
\hline Não & 24 & 52,17 \\
\hline \multicolumn{3}{|c|}{ Como nós (equipe) podemos abordar e incluir essa questão no seu atendimento? } \\
\hline Tratar com carinho o paciente & 21 & 45,65 \\
\hline Dar atenção ao paciente e familiar & 16 & 34,78 \\
\hline Demonstrar amor ao trabalho & 9 & 19,56 \\
\hline Demonstrar respeito ao doente & 9 & 19,56 \\
\hline Demonstrar dedicação ao doente & 7 & 15,21 \\
\hline Ter compaixão & 4 & 8,69 \\
\hline Ter paciência & 5 & 10,86 \\
\hline Ter cuidado no atendimento & 5 & 10,86 \\
\hline Buscar apoio de pessoas religiosas & 2 & 4,34 \\
\hline
\end{tabular}

${ }^{26}$ PEREIRA, Lilian Lopes; DIAS, Ana Cristina Garcia. O familiar cuidador do paciente terminal: o processo de despedida no contexto hospitalar. PSICO, Porto Alegre, v. 38, n. 1, p. 55-65, 2007. Disponível em: $<$ http://revistaseletronicas.pucrs.br/ojs/index.php/revistapsico/article/viewFile/1924/1430 $>$. Acesso em: 22 jan. 2015. 
Escutar e conversar com o paciente e seus familiares

Auxiliar nas dificuldades

$3 \quad 6,52$

Buscar apoio através da Pastoral

Não sabe o que dizer

Fonte: Elaborado pela autora, 2015.

No quadro SPIRIT (Maugans), 63,09\% dos sujeitos pesquisados são da religião católica, $21,23 \%$ da evangélica, $2,17 \%$ da espírita e $13,04 \%$ relatam não pertencer a nenhuma religião. Com relação à importância que dão às suas práticas, 56,52\% praticam atividade na comunidade e 43,48\% não praticam ou realizam somente em casa.

Quanto às práticas de sua religião, $89,13 \%$ as praticam e $17,87 \%$ não as praticam. Dentre as práticas religiosas, as relatadas foram: 34,79\% rezas e orações; $17,87 \%$ rezas e agradecimentos; $30,44 \%$ oração diária; $45,65 \%$ missa e $2,17 \%$ meditação. Quando questionado sobre a restrição das práticas religiosas, 89,13\% sentem falta quando não as praticam e $17,87 \%$ não sentem falta.

Tabela 3 - Quadro SPIRIT (Maugans)

\begin{tabular}{lll}
\hline Questões & Frequência & Porcentagem (\%) \\
\hline Qual é sua religião? & & \\
\hline Católica & 29 & 63,09 \\
Evangélica & 10 & 21,23 \\
Espírita & 1 & 2,17 \\
Nenhuma & 6 & 13,04 \\
\hline
\end{tabular}

Descreva as crenças e práticas de sua religião ou sistema espiritual, se você aceita ou não.

Aceitam e praticam suas crenças $\quad 42 \quad 91,3$

Não aceitam tudo ou aceitam parcialmente as práticas e crenças

$4 \quad 8,7$

Você pertence a alguma igreja, algum templo ou outra forma de comunidade espiritual?

Que importância você dá a isso?

Sim, praticam atividade na comunidade e acham

muito importantes $\quad 26 \quad 56,52$

Não praticam ou praticam em casa somente $\quad 20 \quad 43,48$

Quais são as práticas específicas de sua religião ou comunidade espiritual (ex.: meditação ou reza)?

Praticam atividades de sua religião

41

Não praticam

Rezas e orações

$5 \quad 17,87$

$16 \quad 34,79$


Rezas e agradecimento $\quad 5 \quad 17,87$

Oração diária $\quad 14 \quad 30,44$

Missa $21 \quad 45,65$

Meditação 112,17

Quais os significados e as restrições dessas práticas?

Sente falta quando não praticam suas crenças $\quad 41 \quad 89,13$

Não comentaram ou não sente falta $\quad 5 \quad 17,87$

A qual desses aspectos espirituais/religiosos você gostaria que eu estivesse atento?

Atenção no atendimento ao paciente e familiar $12 \quad 26,08$

$\begin{array}{lll}\text { Respeito aos pacientes e familiares } & 12 & 26,08\end{array}$

Tratar com carinho $\quad 11 \quad 23,91$

Dedicação no atendimento $\quad 11 \quad 23,91$

$\begin{array}{lll}\text { Cuidado durante os procedimentos } & 9 & 19,56\end{array}$

Atendimento com amor $\quad 6 \quad 13,04$

Não sabe o que dizer $\quad 5 \quad 17,87$

Respeito ao paciente e a suas crenças e religião $\quad 4 \quad 8,69$

Compaixão com o paciente $\quad 2 \quad 4,34$

Não precisa pensar na parte espiritual $\quad 1 \quad 2,17$

Dar conforto ao paciente e a familiares $\quad 1 \quad 2,17$

Fonte: Elaborado pela autora, 2015.

Sobre os aspectos espirituais/religiosos que o cuidador informal gostaria que o profissional da saúde estivesse atento, foram relatados os seguintes aspectos: $26,08 \%$ respeito e atenção no atendimento aos pacientes e familiares; $26,08 \%$ tratar com carinho e dedicação; $19,56 \%$ cuidado durante os procedimentos; $13,04 \%$ atendimento com amor; $8,69 \%$ respeito às crenças e religião do paciente; $8,69 \%$ compaixão; $2,71 \%$ dar conforto (Tabela 3).

O grau de satisfação com o cuidado geral dos pacientes foi correlacionado à satisfação com o cuidado espiritual, que demonstra resultado similar ao estudo de Koenig. ${ }^{27}$ As crenças espirituais dos pacientes influenciarão no tipo da assistência que eles esperam. Tais crenças afetam o modo como os pacientes e familiares lidam com a doença e ajudam a manter a esperança e a motivação na direção do cuidado. ${ }^{28}$

${ }^{27}$ KOENIG, Harold. Espiritualidade no cuidado com o paciente: por que, como, quando e o quê. Tradução Giovana Campos. Niterói: Jornalística, 2005. p. 23.

${ }^{28}$ WALL, Richard J. et al. Spiritual care of families in the intensive care unit. Critical Care Medicine, v. 35, p. 1.084-1.090, 2007. Disponível em: $<$ https://depts.washington.edu/respcare/public/hmc_files/ journal_club/articles/20090119/Spiritual_care.pdf $>$. Acesso em: 21 jan. 2015. 
Quando a bioética dialoga com a espiritualidade, remete a um conjunto de aspirações que conduz na direção da responsabilidade, da proteção e do cuidado diante da vida. ${ }^{29}$ Zelar pelo indivíduo espiritualmente caracteriza-se por compreender, relacionar-se, comunicar-se, interagir e estar com o outro. ${ }^{30}$

O cuidar não significa apenas tomar conta, mas avança por caminhos mais profundos que envolvem o ser, como, por exemplo, o processo de assistir, escutar ou tocar a pessoa de forma mais humanizada. ${ }^{31} \mathrm{~A}$ humanização responde pela convivialidade, pela solidariedade, pelo amor e pelo respeito. ${ }^{32}$

O princípio de alteridade pode ser usado para fundamentar a questão bioética que se levanta. Uma vez que significa ser capaz de compreender o outro na plenitude da sua dignidade, dos seus direitos e, sobretudo, da sua diferença. Quanto menos alteridade existe nas relações pessoais e sociais, mais conflitos ocorrem. ${ }^{33}$ Nesse princípio estão englobados valores humanos como o cuidado, a compaixão e a misericórdia. A definição de alteridade é um movimento por meio do qual o indivíduo procura se colocar no lugar do outro e sentir ou vivenciar suas necessidades, dores e limitações. ${ }^{34}$

A alteridade não anula, ao contrário, reforça a liberdade e a dignidade humana, respeita e preserva a privacidade, a subjetividade e a integridade do outro. ${ }^{35} \mathrm{O}$ outro precisa ser conhecido, reconhecido e compreendido. Por isso tem todo o direito de falar e exigir que seja ouvido e escutado, tem todo o direito de ser visto, ser enxergado em sua totalidade.

No contexto da área da saúde, a alteridade como critério fundamental da bioética corresponde às exigências atuais de se atribuir aos pacientes e seus familiares a competência moral e a sua posição de sujeito do seu próprio cuidado, consciente de si mesmo. ${ }^{36} \mathrm{O}$ princípio da alteridade é um fator contribuinte para a busca da humanização no cuidado a saúde. Desse modo, faz repensar as relações dos profissionais da saúde com seus pacientes e familiares.

${ }^{29}$ SOUZA, Waldir. Bioética e Espiritualidade. In: SIQUEIRA, José Eduardo et al. (orgs.). Bioética Clínica: Memórias do XI Congresso Brasileiro de Bioética, III Congresso Brasileiro de Bioética Clínica e II Conferência Internacional sobre o Ensino da Ética. Brasília: CFM/SBB, 2016. 326 p. p. 138.

${ }^{30}$ WALDOW, Vera Regina. Cuidar: expressão humanizadora de enfermagem. 2. ed. Petrópolis: Vozes, 2007. p. 147.

31 SALLES, Álvaro Ângelo. Bioética e processos de religiosidade entre os pacientes com doenças terminais no Brasil. Revista bioética (Impr.), v. 22, n. 3, p. 397-406, 2014. Disponível em: <http://www.scielo.br/ pdf/bioet/v22n3/v22n3a02.pdf $>$. Acesso em: 12 jan. 2015.

32 WALDOW, 2007, p. 65.

${ }^{33}$ HOSSNE, 2011, p. 38.

${ }^{34}$ SÁ, Ana Cristina. Reflexão sobre o cuidar em enfermagem: uma visão do ponto de vista da espiritualidade humana e da atitude crítica. Mundo saúde, v. 33, n. 2, 2009. Disponível em: <http://www.saocamilosp. br/pdf/mundo_saude/67/205a217.pdf > . Acesso em: 21 jan. 2015.

${ }^{35}$ COSTA, 2011, p. 207.

${ }^{36}$ SADALA, Maria Lúcia Araújo. A alteridade: o outro como critério. Rev. esc. enferm. USP, v. 33, n. 4, p. 355-357, 1999. 


\section{Considerações finais}

Os cuidadores que participaram desta pesquisa demonstraram que a espiritualidade faz parte do processo de cuidado ao paciente em cuidados paliativos, pois colabora para a recuperação ou o tratamento do paciente. O indivíduo necessita ser reconhecido como um ser integrante de uma família e que possui uma história prévia que deve ser considerada. Para melhor assisti-lo, sua fé e suas crenças religiosas precisam ser consideradas pelo profissional da saúde. Tanto o paciente como seus familiares querem ser respeitados em sua individualidade, seus direitos e valores. Por fim, os cuidados devem ser centrados nessa individualidade, propiciando, assim, um clima acolhedor, humanizado e de proximidade entre a equipe multidisciplinar, o cuidador e o paciente em tratamento.

Ao compreender a espiritualidade como uma dimensão da vida e que essa faz parte do processo de cuidar, o profissional da saúde poderá, por intermédio do princípio da alteridade, proceder a uma abordagem adequada, avaliar, diagnosticar e intervir no sentido de favorecer o maior conforto possível, guardando as necessidades individuais dos pacientes em cuidados paliativos e seus cuidadores.

\section{Referências}

ARAUJO, Janete; LEITÃO, Elizabeth Maria Pini. O Cuidador do paciente em cuidados paliativos: sobrecarga e desafios. Revista do Hospital Universitário Pedro Ernesto, Rio de Janeiro, ano 11, p. 77-81, abr.jun. 2012. File:///C:/Users/Microsoft/Downloads/8946-31624-1-PB.pdf. Acesso em: 19 dez. 2014.

BALDACHINO, Donia. Spiritual care: being in doing. Preca: Library Malta, 2010.

BARCHIFONTAINE, Christian Paul; PESSINI, Leo. Fundamentos da bioética. São Paulo: Paulus, 1996.

BOFF, Leonardo. Espiritualidade: um caminho de transformação. Rio de Janeiro: Sextante, 2006. CATTANI, Roceli Brum; PERLINI, Nara Marilene Oliveira Girardon. O cuidar do idoso doente no domicílio na voz de cuidadores familiares. Revista Eletrônica de Enfermagem, v. 6, n. 2, 2004. Disponível em: $<$ http://www.revistas.ufg.br/index.php/fen/article/view/812/929>. Acesso em: 16 jan. 2015.

CORRÊA, F. A. A alteridade como critério fundamental e englobante da Bioética. 1993. Tese (Doutorado) - Unicamp, São Paulo, 1993. p. 198.

COSTA, Juliano Xavier Silva; CAETANO, Renato Fernandes. A concepção de alteridade em Lévinas: caminhos para uma formação mais humana no mundo contemporâneo. Revista Eletrônica Igarapé, n. 3, p. 195-210, maio 2014. Disponível em: <http://www.periodicos.unir.br/ index.php/igarape/article/viewFile/861/865>. Acesso em: 15 maio 2015.

DOSSEY, Barbara; KEEGAN, Lynn. Holistic Nursing. A Handbook for Practice. Seventh Edition. Sudbury: Jones and Bartlett Learnig, 2016. p. 143.

HOSSNE, William Saad; SEGRE, Marco Segre. Dos referenciais da bioética - a Alteridade. Revista Centro Universitário São Camilo, São Paulo, v. 5, n. 1, p. 35-40, 2011. Disponível em: $<$ http://www.saocamilo-sp.br/pdf/bioethikos/82/Art04.pdf $>$. Acesso em: 22 fev. 2015.

KOENING, Harold. Espiritualidade no cuidado com o paciente: por que, como, quando e o quê. Tradução Giovana Campos. Niterói: Jornalística, 2005. 
KOENIG, Harold G.; LARSON, David B.; LARSON, Susan S. Religion and coping with serious medical illness. Annals of Pharmacotherapy, v. 35, n. 3, p. 352-359, 2001. Disponível em: $<$ http://www.ncbi.nlm.nih.gov/pubmed/11261534>. Acesso em: 12 fev. 2015.

KOENIG, Harold G.; KING, Dana; CARSON, Verna Benner. Handbook of religion and health. 2nd edition. J. Am Acad Relig., v. 81, n. 2, p. 548-552, 2013.

LAKATOS, Eva Maria. Metodologia cientifica. 6. ed. São Paulo: Atlas, 2011.

MAUGANS, T. A. The spiritual history. Archives of Family Medicine, v. 5, n. 1, p. 11-16, 1996. Disponível em: <http://www.ncbi.nlm.nih.gov/pubmed/8542049>. Acesso em: $11 \mathrm{dez} .2014$.

McCAULEY, Jeanne et al. Daily spiritual experiences folder adults with and without arthritis and the relationship to health outcomes. Arthritis Care \& Research, v. 59, n. 1, p. 122-128, jan. 2015. Disponível em: $<$ http://onlinelibrary.wiley.com/doi/10.1002/art.23246/epdf $>$. Acesso em: 25 jan. 2015.

MIAKO, Kimura et al. Adaptação cultural e validação da Underwood's Daily Spiritual Experience Scale - versão brasileira. Revista da Escola de Enfermagem da USP, v. 46, n. esp., p. 99-126, 2012. Disponível em: <http://www.scielo.br/pdf/reeusp/v46nspe/15.pdf >. Acesso em: 12 jan. 2015.

PEREIRA, Lilian Lopes; DIAS, Ana Cristina Garcia. O familiar cuidador do paciente terminal: o processo de despedida no contexto hospitalar. PSICO, Porto Alegre, v. 38, n. 1, p. 55-65, 2007. Disponível em: <http://revistaseletronicas.pucrs.br/ojs/index.php/revistapsico/article/ viewFile/1924/1430>. Acesso em: 22 jan. 2015.

PUCHALSKI, Christina; ROMER, Anna. L. Taking a spiritual history allows clinicians to understand patients more fully. Journal of Palliative Medicine, v. 3, n. 1, p. 129-137, 2000. Disponível em: <http://smhs.gwu.edu/gwish/sites/gwish/files/takingaspiritualhistorypuchalskiromer.pdf $>$. Acesso em: 21 dez. 2014.

PUGGINA, Ana Claudia Giesbrecht; SILVA, Maria Júlia Paes; ARAUJO, Monica Martins Trovo. Mensagens dos familiares de pacientes em estado de coma: a esperança como elemento comum. Acta Paulista de Enfermagem, v. 21, n. 2, p. 249-255, 2008. Disponível em: <http://www.scielo. br/pdf/ape/v21n2/pt_a03v21n2.pdf>. Acesso em: $18 \mathrm{dez} .2014$.

SÁ, Ana Cristina. Reflexão sobre o cuidar em enfermagem: uma visão do ponto de vista da espiritualidade humana e da atitude crítica. Mundo saúde, v. 33, n. 2, 2009. Disponível em: $<$ http://www.saocamilosp.br/pdf/mundo_saude/67/205a217. pdf $>$. Acesso em: 21 jan. 2015.

SADALA, Maria Lúcia Araújo. A alteridade: o outro como critério. Rev. esc. enferm. USP [online], v. 33, n. 4, p. 355-357, 1999. Disponível em: <http://www.scielo.br/scielo.php?pid=S0080$-62341999000400005 \&$ script=sci_abstract\&tlng=pt $>$. Acesso em: mar 2016.

SALLES, Álvaro Ângelo. Bioética e processos de religiosidade entre os pacientes com doenças terminais no Brasil. Revista bioética (Impr.), v. 22, n. 3, p. 397-406, 2014. Disponível em:

$<$ http://www.scielo.br/pdf/bioet/v22n3/v22n3a02.pdf>. Acesso em: 12 jan. 2015.

SILVA, Cláudia Adriana Moraes; ARCKER, Justina Inês Brunetto Verruck. V. O cuidado paliativo domiciliar sob a ótica de familiares responsáveis pela pessoa portadora de neoplasia. Revista Brasileira de Enfermagem, Brasília, v. 60, n. 2, p. 150-154, mar./abr. 2007. Disponível em: $<$ http://www.scielo.br/pdf/reben/v60n2/a04v60n2.pdf>. Acesso em: 26 jan. 2015.

SOUZA, Waldir. Bioética e Espiritualidade. In. SIQUEIRA, José Eduardo et al. (Orgs.). Bioética Clínica: Memórias do XI Congresso Brasileiro de Bioética, III Congresso Brasileiro de Bioética Clínica e II Conferência Internacional sobre o Ensino da Ética. Brasília: CFM/SBB, 2016. 326 p. UNDERWOOD, Lynn. G. The daily spiritual experience scale: overview and results. Religions, v. 2, n. 1, p. 29-50, 2011. Disponível em: <http://www.mdpi.com/2077-1444/2/1/29/htm>. Acesso em: 21 jan. 2014. 
VEIT, Carina Maria; CASTRO Elisa Kern. Coping religioso/espiritual e câncer de mama: uma revisão sistemática da literatura. Psicologia Saúde e doenças, v. 14, n. 1, p. 1-22, 2013. Disponível em: <http://www.scielo.mec.pt/pdf/psd/v14n1/v14n1a01.pdf>. Acesso em: 18 set. 2014.

WALDOW, Vera Regina. Cuidar: expressão humanizadora de enfermagem. 2. ed. Petrópolis: Vozes, 2007.

WALL, Richard J. et al. Spiritual care of families in the intensive care unit. Critical Care Medicine, v. 35, p. 1.084-1.090, 2007. Disponível em: <https://depts.washington.edu/respcare/ public/hmc_files/journal_club/articles/20090119/Spiritual_care.pdf $>$. Acesso em: 21 jan. 2015. WORLD HEALTH ORGANIZATION. Expert Committee. Cancer, pain relief and palliative care. Geneve, 2002. Disponível em: <http://apps.who.int/iris/bitstream/10665/37896/1/9241544821. pdf>. Acesso em: 16 jan. 2014. 